\title{
Protection of Capacitor Bank Against Switching Transients: An Overview
}

\author{
Vishal V. Vashikar ${ }^{1}$ Dr. S. Prakash ${ }^{2}$ \\ $\left\{{ }^{1}\right.$ vishalvashikar@gmail.com, ${ }^{2}$ prakashacademics@gmail.com $\}$ \\ ${ }^{1}$ Research Scholar EEE Dept., BIHER, Chennai ${ }^{2}$ Supervisor, Professor, EEE dept., BIHER, Chennai, \\ $\mathrm{TN}$, India.
}

\begin{abstract}
In today's world, everyone is tried to make the system faster. To make the system faster, power electronics devices play an important role. The normal industry possesses $80 \%$ of inductive load and has a lagging power factor. The use of electronic equipment in the system causes power quality disturbances. The electricity demand is increasing day by day and it is necessary to serve power with low losses. To overcome this situation switched capacitors are used in the system. But during the switching of capacitors transients are produced in the system and leads to the failure of power electronic equipment. The proposed paper focused on capacitor bank protection against switching transients.
\end{abstract}

Keywords: Capacitor Operation, Transient Current and Voltage, Capacitor Protection Techniques, Reactors.

\section{Introduction}

The electricity demand is increasing nowadays and it is a challenge to serve generated power more effectively and efficiently with low losses. In other words, it is important to improve power quality at the consumer end. The capacitor plays a vital role in power quality improvement. For smooth operation of power system it is necessary to connect or disconnect capacitor bank as per power quality issues, this is possible with the automation only.

When this operation takes place or when the capacitor bank came into operation, it creates switching transients and may lead to failure/damage of highly sensible devices at the consumer end. We cannot avoid the role of power electronics devices which are responsible for the fast operation of the system. So the detailed study of capacitor bank protection against switching transients is proposed in this paper.

The static reactive power can be compensated with the help of switched capacitor banks at the sub-transmission or distribution level. By utilization of capacitor bank, power losses are minimized and power quality improved. [1][2] 


\section{Capacitor Switching Technique:}

The Capacitor is formed by separating the two plates of conducting material by a dielectric medium, and which is capable to store, and gives electrical output as a charge. the various operations that take place in the power grid are responsible for transient voltages and currents. the sudden opening or closing of the circuit breaker changes the circuit parameters and this is responsible to change the values of the current and voltage. All the transients in the power system are seen due to the making and breaking of the contacts of electric components, insertion of energy in the grid, lightning stroke, and static discharge.

The capacitor bank switching at the consumer end is the traditional operation and that may cause the occurrence of transient current and voltage. However, there may be a possibility that the low-frequency transients become severe transients if an end-user has a power factor correction unit, power electronics load, or drives. In other words, the capacitor switching causes damage to customers' equipment like the abnormal operation of speed drives or production lines, malfunction in current or voltage surge protector, a communication network, and results in power quality disturbances.

\section{Capacitor Bank Switching Transients:}

The capacitor voltage is not changed immediately since the switching on of a capacitor, the voltage appeared at the terminals is zero. Activation of a capacitor bank affects the system voltage and instantaneously voltage is dropped toward zero to attempt fast voltage recovery and finally, a fluctuating voltage overlap/affects the system frequency. During the immediate activation or under abnormal conditions the observed voltage is 2 times larger than the regular peak voltage. it means that the voltage peak value is associated with instantaneous system voltage. At the distribution level, the overvoltage value varies from 1.1 to $1.6 \mathrm{pu}$.

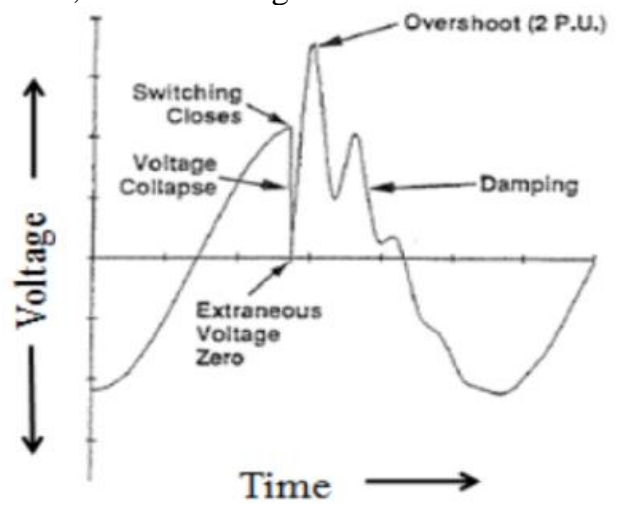

Fig.1. Switching Transient

The current drawn by the electric equipment during energization is called the Inrush current. When the supply is on, the current is set into the circuit, this current attempts the peak value and is greater than the normal operating current value. Then the current value decreases gradually and sets up to its normal value. if the equipment is operated with inrush current it may be overheated and breakdown takes place. this failure depends on the value of inrush current and duration. 


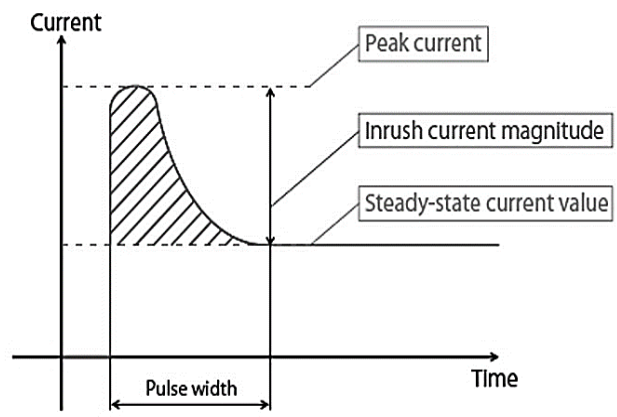

Fig.2. Inrush current production

After insertion of the capacitor bank, when it energized the first time the value of the inrush current is greater than the normal value. This is due to the high initial current drawn by the capacitor for charging. To limit this initial current fuses and circuit breakers are used.

A transient is a phenomenon that is generally seen by abnormal operations of the power system, which concludes into a negative impact on the consumer. The abnormal operations of the power system include lightning strokes, various faults, and switching operations, etc.

The common causes for the production of Inrush Current in the power system are,

- Transformer impedance, high distance cable lay.

- Low response of the power factor correction unit.

- High nonlinear loads or increased use of power electronic devices.

- frequently transformer switching.

- frequently capacitor bank switching.

Due to all the above reasons, the production of inrush current takes place and is harmful to the power system and its equipment. The common effects are,

- Heating of the power system equipment.

- Increased losses.

- Decreases the efficiency of the system.

- Abnormal operation of the equipment which results in shut down or maintenance.

\section{Capacitor Bank Protection Techniques:}

\subsection{Insertion of resistance}

The insertion of resistance in between the system and capacitor banks is one of the common methods is used to protect the bank. capacitor bank plays a vital role to improve power factor and power quality. During the switching of the capacitor bank, the excessive voltage is dropped in the resistor. And the system is isolated from power quality issues. To maintain the power factor and avoiding the penalty from system utility the capacitor banks are used. The insertion of the resistor prevents the capacitor bank damage as well as the nearby connected equipment. [3][4][5]

\subsection{Protection against transients}

Most of the industry possesses inductive load. So the poor power factor and power loss are generally seen at this load. To improve the power factor and reduction of losses the 
capacitor banks are inserted. But during the capacitor bank energization, switching transients have occurred. These transients will affect the nearby connected equipment. By using the reactor we can limit the transient values within the permissible limit. [6]

\subsection{Protection against overvoltage}

The protection of the capacitor bank against overvoltage is required to avoid permanent damage to the bank. The abnormal conditions or faults may result in overvoltage. This will affect the thin conducting material of the capacitor bank. To avoid internal failure of the capacitor bank resistance or reactances are used to suppress the overvoltage. [7]

\subsection{Current limiting reactors $(C L R)$}

The reactor is one of the best solutions to limit the voltage and current transients. The Reactor is formed by a coil with a large number of turns and has a high value of resistance. The reactors also limit the value of the short circuit current by which the power system equipment gets protected. The reactors also help to protect the circuit breakers with various ratings used in the power system. According to the strength of the circuit breaker, it is capable to limit the value of the short circuit current. During the modification of the power system, if we don't want to replace the existing circuit breaker, we can put a reactor of proper rating which saves time and money.

\section{Conclusion}

To reduce the power loss and improve the power quality, the capacitor banks are introduced at the consumer end. Meanwhile, it maintains the system's stability. During the switching operation of the capacitor bank, the generated transients are suppressed by introducing a reactor or resistor into the system. The current limiting reactor is one of the best solutions to control switching transients during capacitor bank operation. In this paper, the economical growth, as well as the efficient way of capacitor bank utilization, is considered.

\section{References}

[1] M.S.Javadi, A.E. Nedzad, Pierlugi Siano and M.S.khan, "Shunt capacitor placement in radial distribution networks considering switching transient decision-making approach," Elsevier, Electrical Power and Energy Systems 92(2017)167-180.

[2] A. A. Jambukar and M. F. A. R. Satarkar, "Simulation Analysis of Switching of Shunt Capacitor Bank in 220/22 kV Substation," 2018 Second International Conference on Intelligent Computing and Control Systems (ICICCS), Madurai, India, 2018, pp. 1554-1559, doi: 10.1109/ICCONS.2018.8663055.

[3] L. V. Teli and H. T. Jadhav, "A Review on Protection of Capacitor in Power Quality Industry," 2018 International Conference on Current Trends towards Converging Technologies (ICCTCT), Coimbatore, India, 2018, pp. 1-5, doi: 10.1109/ICCTCT.2018.8550935.

[4] B. Sreewirote and A. Ngaopitakkul, "Analysis of power quality issue in arc furnace capacitor bank system," 2016 19th International Conference on Electrical Machines and Systems (ICEMS), Chiba, Japan, 2016, pp. 1-5.

[5] S. Jahdi and Loi Lei Lai, "Affects of TCSC usages on Distance protection and Voltage profile of a system; a novel," 2011 IEEE 33rd International Telecommunications Energy Conference (INTELEC), Amsterdam, Netherlands, 2011, pp. 1-9, doi: 10.1109/INTLEC.2011.6099829.

[6] M. Devi Atluri, B. R. Kumar and U. V. Reddy, "Comparative study of passive transients controlling methods during capacitor bank switching," 2016 International Conference on 
Signal Processing, Communication, Power and Embedded System (SCOPES), Paralakhemundi, 2016, pp. 131-134, doi: 10.1109/SCOPES.2016.7955676.

[7] J. Wang, M. Ibrahim, Z. Gajić and M. M. Saha, "Internal failure detection and protection on capacitor banks," 13th International Conference on Development in Power System Protection 2016 (DPSP), Edinburgh, UK, 2016, pp. 1-6, doi: 10.1049/cp.2016.0017.

[8] A. Dzionk and R. Małkowski, "Activity coordination of capacitor banks and power transformer controllers in order to reduce power losses in the MV grid," 2016 10th International Conference on Compatibility, Power Electronics and Power Engineering (CPE-POWERING), Bydgoszcz, Poland, 2016, pp. 27-32, doi: 10.1109/CPE.2016.7544153. 